\title{
Drug Use and Harm Reduction Model: Responding to the Health Challenge of Injecting Drug Users in Bangladesh
}

\author{
Sonia Sharmin \\ Correspondence: Sonia Sharmin, Department of Sociology, University of Dhaka, Dhaka 1000, Bangladesh. Tel: \\ 880-171-108-2808. E-mail: soniasharmin_bd@hotmail.com
}

\author{
Received: May 7, 2013 Accepted: May 22, 2013 Available online: June 1, 2013 \\ doi:10.11114/ijsss.v1i2.136 \\ URL: http://dx.doi.org/10.11114/ijsss.v1i2.136
}

\begin{abstract}
This paper attempts to investigate the application of Harm Reduction Model that is largely in practice, in the context of Bangladesh. The Injective Drug Users (IDU) is considered to be most susceptible to blood borne diseases and Harm Reduction approach is vital in containing the epidemic of such contagion and depleting the threat eventually. This paper applies mixed methods to identify the commitment and activity of Drop in Centres (DIC's) of major NGOs, which are locally and globally funded, with the support of local government to attain the Health Millennium Development Goal (MDG) of 2021. The paper is investigative to the operational effectiveness of Harm Reduction Model and suggestive to social policy development.
\end{abstract}

Keywords: Harm Reduction Model, Injective Drug User, Drop in Center, HIV, HCV

\section{Introduction and Background}

Drug addiction has become a worldwide problem which is threatening the basic pillars of human society- no age or social level is exempted from this curse (Chowdhury, 2002). Drug addiction, in modern age, has been considered as a fatal social problem and almost endemic to human existence. Bangladesh is an important center of drug use and distribution in terms of its geographic location. According to different governmental and non-governmental organizations approximately 50 lac people are drug addicted, among them $91 \%$ are teenagers and youths and one and half lac are women who are now habituated in drugs (The Daily Star, 7 July, 2010). The incidence of HIV/AIDS and hepatitis C infection in Bangladesh is going to reach alarming level as people have been responding to many challenges affecting their lives, health and well-being through the transmission of these blood-borne viruses. The prevalence of HIV in Bangladesh is less than 1\% (last surveillance conducted in 2007) and the estimated number of HIV positive cases in the country is around 7500 (NASP/ MOHFW, 2008). It is now apparent that the main route of HIV and HCV transmission is through injecting drug use, re-use or sharing of injecting equipment's. Heightened by the advent of risk behavior among hidden populations of drug users there has been increasing interest in reaching and providing services directed to drug treatment and health care. Harm reduction has become central theme in minimizing risk behavior as a central component of wider HIV prevention. The problem is that the effectiveness of the harm reduction program in reducing HIV and HCV risk behavior are not clear due to lack of some sort of support services, barriers in running needle syringe exchange program (NSEP) and lack of awareness in the transmission of HIV and HCV (Habib, 2009). Specifically, the aims of this research are to explore the role of harm reduction in preventing HIV and HCV transmission, the need for safer environment and barriers in getting harm reduction services and to make some suggestions for harm minimization based on the findings.

Significant proportion of the scholars, working with the issues of social development, devout their efforts in reducing the compulsive use of drug. Experts working in corrections agree that public health measures do not reduce drug addiction. Yet our government and private enterprises invest money, time and great efforts in the growth and maintenance of anti-addiction projects. A drug-free or addiction-free society may be the ideal but in reality, substance use and compulsive behaviors like gambling are part of our life, and have been a component of virtually every society from the dawn of recorded history.

In the study by Hope et al (2010), factor analysis method and association tests were run on a survey conducted on IDUs of England, Wales and Northern Ireland. High degree of association was found between frequency of 
injecting drug use and morbidity and healthcare costs. In another study Dickson-Gomez (2010) suggested, HIV risk is more associated to the distribution pattern of injecting drugs and practice of drug intake. Social behavior towards injecting drug users in disbursed areas of study site found different degrees of association with HIV risk among IDUs. In these studies, the ethics of research with drug users were focused. Many of the traditional studies failed to provide ethical protection to the vulnerable focus group by putting all drug users in a 'homogenous group', disregarding the gender concentration. Consequently, specific recommendations are crucial in regards to how research with such population should proceed (Bell \& Selmon, 2013)

To minimize the harmful consequences of personal drug use and associated high-risk behaviors, harm reduction is founded on a set of pragmatic principles and compassionate strategies designed. It is a grassroots movement that has emerged as a middle path of the polarized opposites of the moral and medical models that promises to provide humane and practical help for drug users, their families, and our communities (Marlatt, 1998).

The risk of HIV and HCV infection among Injective Drug Users (IDUs) has grew out as an increasingly serious social and public health problems in Bangladesh. The limited public health response to hepatitis $\mathrm{C}$ and HIV is due to route of transmission. IDUs are fragmented, stigmatized, and marginalized in Bangladeshi society. Majority of the population who are mostly infected by HIV or HCV are the hidden populations of drug users to who drug treatment and health care needs to be reached. User-friendly education, counseling, sterile needle syringe distribution, condom supply and other community based interventions can enhance an individual's perceptions of the severity of the personal threat of HIV and HCV and also can reduce the chances of getting infected by the blood borne diseases. Health promotion can be successfully achieved if the implication of these interventions play major role. In this regard, the primary global strategy to reduce transmission of HIV and HCV among IDUs is to increase access to sterile syringes. Harm reduction approaches for HIV/AIDS, HCV and other blood borne virus prevention has developed to stem the frightening rate of HIV infection among members of certain at-risk populations. 'Harm reduction principles that are unique to HIV and HCV intervention include: 1) the ability and competence of marginalized people to make choices and changes in their lives; 2) the need for individuals and communities affected by AIDS risk behavior to be involved in the organization and creation of strategies for harm reduction interventions; and 3) the diversity of people affected by HIV/AIDS or HCV and the necessity for outreach and services that reflect this diversity' (Peterson, et al. 1998).

A major weakness of past researches overwhelmingly emphasizes on hepatitis C and HIV and regulating drug users by the model of harm reduction, leaving behind the issues like IDUs and their maintenance of risk behavior like sharing needles/ syringes, unprotected sex etc. Few researches have been done in Bangladesh on whether the present harm reduction model is effective at all and the barriers and gaps of harm reduction model. Importance of the relatively safe injecting room has also been excluded from this model which is not the case in other country. In particular there are a number of gaps in the current understanding of harm reduction model responding to the health challenge of Bangladesh. Therefore, it is time to assess whether the main aspects of HIV and $\mathrm{HCV}$ risk behavior have changed in recent times in order to sustain achievements to reduce rates of $\mathrm{HCV}$ and HIV.

The present study conducts the behavioral context of self-reported HIV and HCV status of persons who attend needle and syringe outlets. The main purpose of the study is to assess the current state of the hepatitis C and HIV epidemic and associated risk factors in a harm reduction environment and to explore the reasons of using drug use in Bangladesh. Prevention programs have been operated by few international non-governmental organizations (NGO) in Bangladesh, CARE Bangladesh for IDUs since 1998. Harm reduction services including NSEP and oral drug substitution are yet to be legalized in Bangladesh, despite which CARE Bangladesh runs a NSEP which is operated primarily through outreach workers and has several drop-in centers within the community through which they provide services for sexually transmitted infections (STI), abscess management, rest and recreational facilities, HIV/AIDS awareness generation, male condoms and needle/syringe exchange. Furthermore, two week detoxification camps are organized intermittently. In this regard, this study will focus the role harm reduction is playing currently to reduce harm related drug use.

\section{The Concept of Harm Reduction}

At present there is no definite definition of harm reduction. One working definition is "An attempt to ameliorate the adverse health, social or economic consequences of mood-altering substances without necessarily requiring a reduction in the consumption of these substances" (Heather, et.al, 1993).

David Purchase, director of the North American Syringe Exchange Network, known for his work in establishing the first U.S. syringe exchange program, denied that harm reduction is a front for any political agenda (i.e., drug legalization), describing it instead as a 'living thing' not to be found in the field of dogma. He put emphasis on 
that the essence of harm reduction is an individualized approach to positive changes in behavior: "Harm reduction is against harm, neutral on the use of drugs per se, and in favor of any positive change, as defined by the person making the change" (Marlatt, 1998).

In response to harm reduction Diane Riley and Pat O'Hare explained harm reduction as a policy which involves setting up of realistic and immediate goals to be achieved in steps on the way to risk-free use or if appropriate, abstinence; consequently, it is an approach that is characterized by pragmatism. Harm reduction approach attempts to recognize, ration, and decrease the adverse consequences of drug use at a number of levels, not just that of society as a whole. In a harm reduction framework, the term risk is used to describe the probability of drug-taking behavior resulting in any of a number of consequences (Inciardi \& Harrison, 2000).

Critics of harm reduction denied it as being overly permissive in its rejection of strict "zero-tolerance" policies and its promotion of alternatives to abstinence. Some critics have gone so far as to label the entire harm reduction movement a "front" for drug legalization (Marlatt, 1998).

\section{Responding to the Challenge}

Harm reduction is commonly misunderstood and misperceived as encouraging or ignoring substance use; and in the case of illicit drugs, encouraging violation of the law. It's been common that some community members have moral values that oppose substance use and gambling. Other community stakeholders have differing opinions on what is the cause or the best way to deal with addiction. They perhaps unfamiliar or uncomfortable with harm reduction as a legitimate and accepted approach. In either case, educating community stakeholders is critical and addressing substance use and gambling as health and social issues rather than moral or criminal concerns is key.

At the National AIDS Policy in early 1997, while Bangladesh Government initiated harm reduction program, there were challenges in much of the intervention areas. One is that some strategies in harm reduction program such as the operation of NSEP imply ignoring illicit drug use and or potentially health damaging forms of behavior. In addition, the concentration of Harm Reduction Model is directed towards the heavy users, leaving a substantial number of moderate users out of the span of consideration.

In British Columbia Ministry of Health community guide, the common concern about harm reduction is that harm reduction encourages drug use among non-drug users. This is based on the notions that harm reduction 'sends out the wrong signal' and undermines primary prevention efforts. To some, the notion of helping drug users to stay alive, reduce their exposure to risk and become healthier may encourage non-users to regard drug use as safe and to want to start using drugs. This view underestimates the complexity of factors that shape people's decisions, ignores numerous scientific studies that have found no evidence that the introduction of needle exchange or other harm reduction programs increases drug use.

Harm reduction enables drug use and entrenches addictive behavior. For those who are unwilling and unable to quit, relapse into drug use. Harm reduction is often the first or only link that drug users have to the health and social service system and, as such, it is a gateway to addiction treatment. Harm reduction services escalate the chances that drug users will re-engage in broader society, lead productive lives and abandon drugs, in place of contracting and transmitting infectious diseases and/or succumbing to drug overdose death.

Harm reduction increases disorder and threatens public safety and health. Often referred to as the 'honey pot effect', this concern assumes that harm reduction programs will attract drug dealers and compromise the safety and well-being of the community. Evidence has conclusively demonstrated that harm reduction programs renders contrasting results. They have a positive impact on public health by reducing the prevalence of blood borne viruses such as HIV and hepatitis C. Needle exchange programs often recover more needles than distributed, meaning fewer used needles discarded publicly. Supervised injection facilities diminish the practice of public injections by providing a safe, indoor alternative to open drug use. Harm reduction service providers also ensure that drug trafficking is strictly policed, carrying out nationwide activities.

Harm reduction is a 'Trojan Horse' for decriminalization and legalization. Harm reduction strategies attempt to deal with evils from drug use as it occurs within the current global regulatory regime. Some advocates of harm reduction want to see changes in the way governments have been attempting to control the trade and use of currently illegal drugs; others do not. Harm reduction itself is neutral regarding the question of legalization. The philosophy of harm reduction applies equally to alcohol and tobacco use, which is legal in most countries (British Columbia. Ministry of Health, 2005).

Harm reduction strategies often involve working with highly marginalized populations. For instance, the socially and economically disadvantaged, street youth, the homeless, criminal justice populations, and those who use 
drugs by injection are marginalized group. As hierarchy of stigma is associated with addiction, then these are the most stigmatized groups. Recognizing a problem with alcohol, other drugs or gambling is tough and seeking help can be even more difficult. Addicted people are often isolated, ambivalent, and fearful of being judged or fearful of legal consequences, and resistant to confrontation. Even if anybody wants to change their behavior, goals are difficult to set, achieve and maintain. Harm reduction strategies are humane, inclusive and non-coercive.

Adequate resources are needed to initiate and maintain harm reduction within the community which is not possible to stand for all the countries. It does little good to implement a program, demonstrate the success of the program, and then be unable to sustain it because of inadequate resources. Harm reduction service are relatively inexpensive and cost effective. They increase financial return on investment for the individual and for society by reducing costs associated with criminal activity, morbidity, unemployment, risk behaviors and the transmission of infectious disease rather than using limited resources to treat complications of advanced illness.

Gaps exist in the evidence base to support effective harm reduction programs and services for youth. Youth are most often the target of prevention programs with an undifferentiated goal of abstinence. For street-involved youth and those youth who are homeless, substance use patterns differ dramatically from adolescents in school and living at home. Street-involved youth tend to be at very high risk for harm from blood borne infections such as HIV, sexually transmitted diseases (STI), pregnancy, victimization, and physical abuse, participation in sex trade and criminal activities, drug overdose and recklessness. Harm reduction initiatives for high-risk youth are far more acceptable, warranted and critical from the perspective of health and community safety (James, 2007).

Another common challenge to harm reduction is that it is assumed as western model culturally inappropriate for Muslim society. Currently this has been an increasingly difficult position to maintain given the range of indigenous harm reduction programs successfully operating in other parts of Asia.

A plethora of studies indicated extremely repressive laws have had little effect other than to further disenfranchise drug users. Consequently the IDUs are driven out of controllable regime. More amendments designed to decriminalize possession of injecting equipment and to enable authorized workers to legally supply such equipment in certain areas. Furthermore, it is unrealistic to arrange treatment for several thousand IDUs for a short time given the fact that drug treatment is costly. An additional problem with this strategy is that many IDUs do not want to enter treatment often leaving before they are ready while others relapse. These factors provide a framework within which specific harm reduction intervention can be planned, implemented, evaluated and it necessary modified.

One of the major factors hindering NSEP from operating more effectively is a lack of appropriate government support for NSEP programs and workers when they are attacked by police residents' media and politicians. Their support must be increased if NSEP programs are to succeed. At the same time legal uncertainties and obstacles to effective NSEP must be addressed (Habib, 2004).

Harm reduction is based on service model on the theory of establishing contact with injection drug users, and putting them in touch with services that meet their most immediate needs. Harm reduction model is concerned with helping people reducing the harmful effects on lives. In their interactions with NSP staff, they receive clear harm reduction messages about safer injection, health care, and drug treatment which lead them to perceive behavior and change their risky behavior. Thus, harm reduction is the model which fulfills all requirements of other models which is described earlier. 


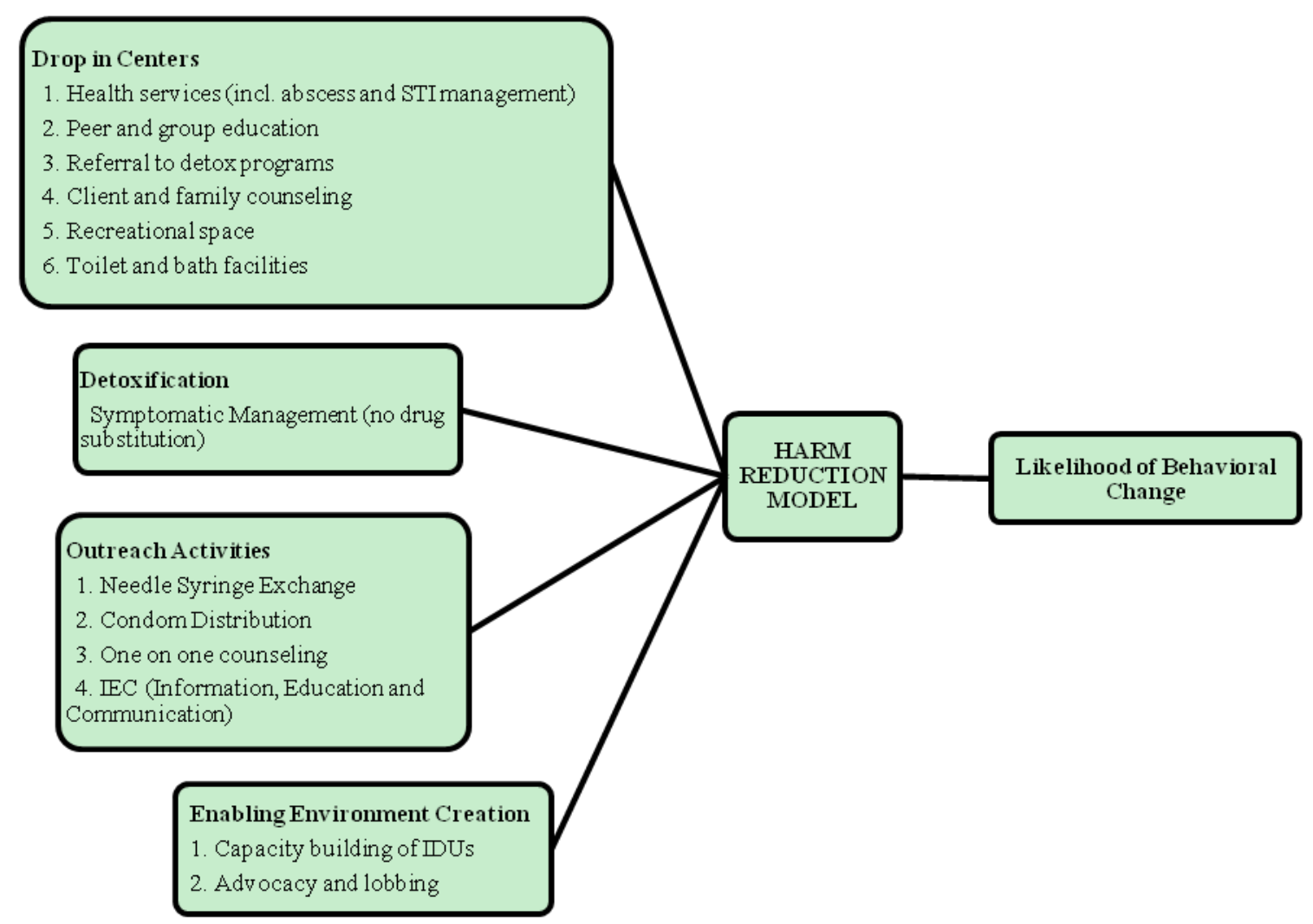

Figure 1. Conceptual Framework

\section{Research Objective}

Drug injectors require health promotion information and accessible services in order to change behavior. The logic is to have access into the provision of sterile injecting equipment that will help to improve the welfare of individual users. Provision of more syringe programs and availability- coupled with education and reduction of barriers and safer environment- could lead to saving the lives of some users. To support the aim of the study and to provide answers to the research questions, research objectives formulated are:

i. To examine whether provisions of the model meet the needs of drug users and contribute to the promotion of safer behavior in scheming hepatitis $\mathrm{C}$ and HIV.

ii. To explore the role of the needle and syringe program in preventing HIV and HCV transmission amongst injecting drug users.

iii. To determine the need for safer injecting environment interventions in reducing risk behavior of injecting drug users.

iv. To identify barriers for getting harm reduction services by IDUs.

\subsection{Hypotheses of the Study}

On the basis of research objectives drawn in the beginning of the study, and citing a plethora of literatures in related field, the study has formulated some hypotheses of significance.

Therefore, the hypotheses necessary to be devised and researched are

1. Implementation of a needle-exchange program (NEP) leads to lower the sharing behavior among injecting drug users.

2. Harm reduction policy influences service seeking patterns of IDUs.

3. Harm reduction service leads to increase the awareness of HCV and HIV

4. Safer environment interventions cause the reduction of drug related harm. 
5. Barriers toward the use of NSP (Needle Syringe Program) lead to increase drug related harm.

\section{Methodology}

Due to the sensitive nature of the subject to be investigated mixed method has been considered as an appropriate method. The survey is carried out by using interview schedule, which is semi-structured questionnaire. The questionnaire was designed consisting of both open and close-ended questions, which included qualitative and quantitative components. The open ended questions were designed to identify requirements to improve existing harm reduction services available in DICs, what information they get regarding HIV/AIDS, HCV and STIs. Considering a number of factors- scope, budget, time and precision, a survey by face to face interview was chosen for this study as the most flexible instrument to use. It is the most popular method in social and behavioral research, employing verbal questioning as its principle technique of data collection, attracting a relatively high response rate.

Similarly to explore the range of opinions on a topic of interest, to understand wider context of drug use and harm reduction services focus group discussion (FGD) has been used in this research as a method of data collection together with survey method. It is an excellent medium for social science research measuring prevalence, risk practices, knowledge, beliefs and attitudes and understanding associations between variables. In addition, for the focus group discussion semi-structured questions were formed. During the period of data collection, a well-organized field diary and sound recorder were used.

To get broad range of information and to get access to IDUs who are hidden population, Drop in Centers (DICs) and spots (place where sterile needles and syringes are distributed by outreach workers and where IDUs inject drugs) are mainly selected as they are the contact point for many drug users who come to take services from there and as the research topic of this study is to focus on the effectiveness of harm reduction model which is followed only in DICs. They run a Needle/Syringe Exchange Program (NSEP) which is operated primarily through outreach workers and provides various services outlined in Figure 1.Therefore, in terms of a response rate- the researcher found that it would be helpful to obtain higher consent rates from these DICs, where the users would also get the opportunity to express information about current hepatitis C and HIV and other drug related issues.

Purposive sampling procedure is adopted by the researchers where the judgment of an expert is in application with specific purpose in mind. To select members of a difficult-to-reach, specialized population like injecting drug users' purposive sampling procedure is more acceptable (Stimson, Fitch, \& Rhodes, 1998). Respondents were also contacted through networking and snowballing at various sites using outreach drug workers who were ex-drug users and worked as mediators to their associates.

Based on the research objective and hypotheses, questionnaire was consisted of six sections which consists three demographic variable related questions, eight questions about drug use pattern, five questions regarding sharing behavior of injection equipment, cleaning of injection equipment, and disposal of used injection equipment, twenty nine questions involve service seeking pattern of harm reduction, nine questions concerning barriers to NSP use and nine questions on knowledge about HIV/AIDS and HCV risk behaviors, sources of HIV and HCV information etc. The majority of the questions under each of the sections have an open-ended part for collecting answers with further elaboration.

\section{Findings}

Drug abuse is a huge barrier to the way of development and prosperity of our nation. It creates number of problems in life, especially in its individual, intimate, communal and national contexts. The main purpose of this study is to understand HIV and HCV related risk behavior and the efficacy of the harm reduction model in understanding how risk behavior is individually and socially organized. This part will focus on the focal points of this research and will relate them to the findings of the study. The hypothesis of the studies will be illustrated in light of the findings, and the following will be explicated in utter detail.

On the basis of the evidence presented in this study, in some aspects IDUs expressed ideas consistent with the model and in others the opinions and practices of some IDUs do not match the principles of the model completely. In table 1, the significance of crucial hypothesis is checked for sample IDUs. Chi-square test is applied to examine the reliance of total number of HIV positive or negative and the potential relationship between abscesses due to injection, with larger periods of drug injecting co-varying with positive HIV result. A $2 \times 2$ table chi-square test has been conducted on abscess due to injection and HIV relationship, where the significance of the connotation is supported by the strength of the representation by derived results. 
The dependence test conducted on condoms received by the respondents and being HIV positive is significant in their implication as well. The significance collected from $87 \%$ of the HIV positive respondents is supported by the respond that knowing they are HIV positive the group is concerned about the spread of disease and spontaneously collect condoms to contain the spread of HIV infection . In addition chi-square test has been conducted on treatment of sexually transmitted diseases with HIV positive and non-positive. From $61 \%$ of respondents the reliability test suggests that, HIV spreads significantly if sexually transmitted diseases are not treated properly. Addressing sexually transmitted diseases properly would bring down the number of HIV positive as diagnosed in early phase and possess significant relationships. Similarly to this study, the dependence is found significant among HIV positives to discriminatory behavior of doctors and diagnose services provided to the respondents. The significance is indicative of; the social stereotypes toward IDUs would instigate the expansion of HIV more than anything. If discrimination can be eliminated from medical service providers the number of HIV positive will significantly fall.

Table 1. Demographic characteristics and risk behavior of injecting drug users for HIV

\begin{tabular}{|llll|}
\hline Variables & $\begin{array}{l}\text { HIVPositive29\% } \\
(64 / 281)\end{array}$ & $\begin{array}{l}\text { HIVNegative71\% } \\
(218 / 281)\end{array}$ & $\chi^{2}$ \\
Age in years & 31.27 (s.d.10.36) & 32.21 (s.d.8.77) & $282(0.00)$ \\
Abscess due to injection & & & \\
Yes & $11.7 \%(33 / 61)$ & $71.2 \%(154 / 216)$ & 6.984 \\
No & $45.9 \%(28 / 61)$ & $28.2 \%(61 / 216)$ & $(0.03)$ \\
$\begin{array}{l}\text { Receiving condom } \\
\text { Yes }\end{array}$ & $87 \%(55 / 63)$ & $95.8 \%(209 / 218)$ & 6.316 \\
$\begin{array}{l}\text { No } \\
\text { Treatment for** } \\
\text { sexually transmitted } \\
\text { diseases }\end{array}$ & $12.6 \%(8 / 63)$ & $4.1 \%(9 / 218)$ & $(0.018)$ \\
$\begin{array}{l}\text { Yes } \\
\text { No }\end{array}$ & $61 \%(36 / 59)$ & & \\
$\begin{array}{l}\text { Discriminated getting } \\
\text { medical attention from } \\
\text { public hospitals }\end{array}$ & $38.9 \%(23 / 59)$ & $80.9 \%(174 / 215)$ & 10.255 \\
Yes & & $19 \%(41 / 215)$ & $(0.01)$ \\
No & $54.9 \%(28 / 51)$ & $71.1 \%(133 / 187)$ & 4.818 \\
\hline
\end{tabular}

** Sexually transmitted diseases contain Syphilis, Gonorrhea, Chlamydia, Trichomoniasis, Genital Score etc.

As observed from the following table that identifies the extensiveness of risk behavior of injective drug users, it is necessary to test the impact of DICs to altering the risk behavior of IDUs to a less risky intake behavior. High degree of significance in practicing cleaner sharing of injective intake is found among samples visiting DICs more frequently compared to samples that visit DICs occasionally. It is noted that, while due to regular injective practices, abscess as an expected disease cannot be averted; in parallel to the level of sharing practices, DICs medical support system significantly contributing to keep the epidemic at bay. A high degree of significance in chi-squared test in the contrasting reliance is found within the sample. Putatively DICs are playing role to reduce HIV spread through enforcing harm reduction approach, the sample statistics suggest significant risk reduction, altering samples attitude towards safer sexual practices. Awareness generation and supplementing safer sexual components has significantly dropped unsafe sexual contact that induces possibility of outbreak of sexually transmitted disease. 
Table 2. Risk behavior of injecting drug users

\begin{tabular}{|c|c|c|c|}
\hline $\mathrm{H}_{0}$ hypothesis & $\mathrm{H}_{1}$ hypothesis & $\chi^{2}$ Test statistics & Decision \\
\hline $\begin{array}{l}\text { No dependence between recent } \\
\text { sharing and clean practices }\end{array}$ & $\begin{array}{l}\text { Recent sharing follows higher degree } \\
\text { of cleaning practices, among IDUs } \\
\text { exposed to harm reduction practices }\end{array}$ & $\begin{array}{l}27.198 * * \\
(0.000)\end{array}$ & Reject $\mathrm{H}_{0}$. \\
\hline $\begin{array}{l}\text { No dependence between abscess } \\
\text { due to injection and treatment for } \\
\text { abscess received }\end{array}$ & $\begin{array}{l}\text { Association signifies that, though } \\
\text { many of the respondents are having } \\
\text { abscess due to injection, they are } \\
\text { receiving treatment for abscess in } \\
\text { similar rate in DICs }\end{array}$ & $\begin{array}{l}247.95^{* *} \\
(0.000)\end{array}$ & Reject $\mathrm{H}_{0}$. \\
\hline $\begin{array}{l}\text { No significant dependence } \\
\text { between condom used recently } \\
\text { and condom collected from DIC }\end{array}$ & $\begin{array}{l}\text { Higher degree of condom usage in } \\
\text { IDUs, receiving condoms from DICs } \\
\text { in post-period high risk sexual } \\
\text { contacts }\end{array}$ & $\begin{array}{l}124.328 * * \\
(0.000)\end{array}$ & Reject $\mathrm{H}_{0}$. \\
\hline $\begin{array}{l}\text { No dependence between } \\
\text { awareness of HIV and education } \\
\text { from DICs }\end{array}$ & $\begin{array}{l}\text { DICs are successfully generating } \\
\text { awareness in IDUs, that leads to steep } \\
\text { decline in HIV spreading among } \\
\text { IDUs }\end{array}$ & $\begin{array}{l}78.512 * * \\
(0.000)\end{array}$ & Reject $\mathrm{H}_{0}$. \\
\hline
\end{tabular}

A major focus of the study is to map the delivery service seeking pattern of Harm Reduction model distributed in the DICs in Bangladesh is found in Figure 2. It is undeniable; barriers to Needle Exchange Program (NEP) in Bangladesh are prominent due to numerous social prejudice and community barriers. IDUs are exposed to a high degree of social stigma in absence of safe injective location. In desperation of drug intake, risk behavior of unprotected needle sharing cause the drug taker population to infuse into non-drug takers increasing the potential of contamination. It is crucial to contain the behavior and reduce the spread of drug use with a knowledge approach. It is observed from Figure 2, learning of blood borne disease, that eventually generates awareness to reduce drug taking behavior among IDUs is profound in the samples ( $91 \%$ approximately) that visit DICs frequently and intermittently. A surprising $63 \%$ of the drug users are deprived of public and private medical attention largely due to social stigma. DICs are playing an important role healing this population of sexually transmitted diseases (STI) and containing the contagion within a small container. Of the entire population of IDUs, $74 \%$ is receiving medical attention in DICs, $73 \%$ is tested for HIV and $76 \%$ is receiving treatment for STIs. Such finding is satisfactory to the objectives of harm reduction model and services of DICs in Bangladesh that are imparting the model into practice, successfully deteriorating the threat of blood borne disease. The delivery of awareness is causing the decay of social stigma, and the population instead of instigating the sharing process of injective drug use is being deployed to alter risk behavior of the population still in risk.

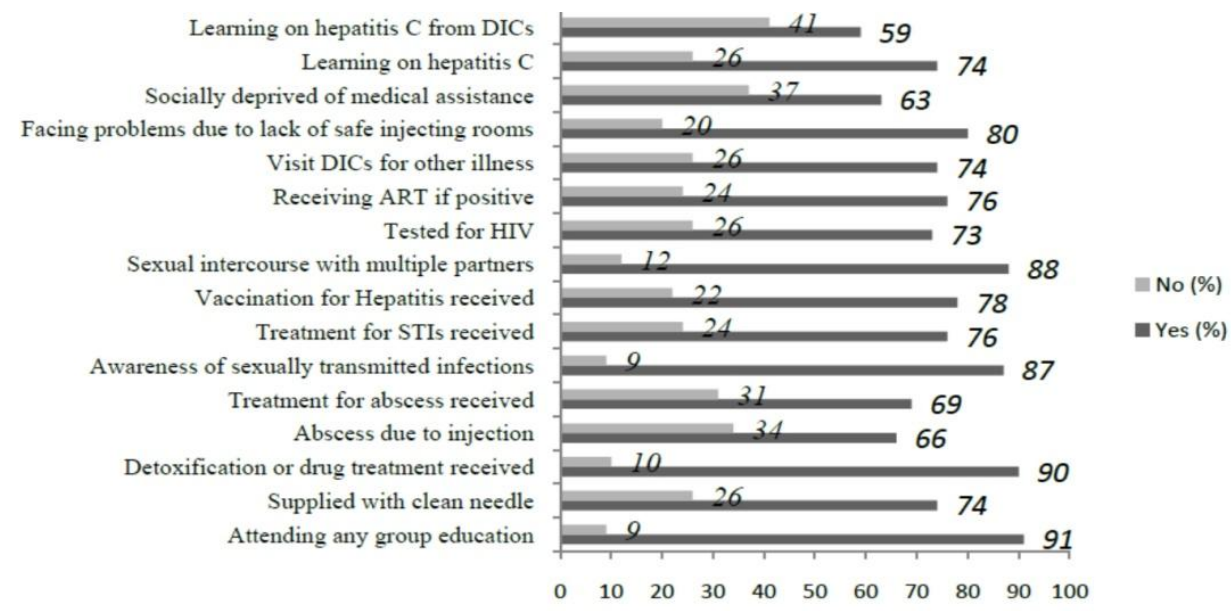

Figure 2. Service Seeking Pattern of Harm Reduction (Sample responds) 
Needle exchange program (NEP) of the DICs is a major determinant of DICs application of harm reduction approach. In its process of proper NEP distribution, barriers cannot be averted. The barriers of NEP revolve in the circle of social stigma and the inclination of IDUs to receive a safer injective approach. It is still daunting to learn that $17 \%$ of the IDUs are unaware of NEP delivered by DICs, 24\% complains on the limited availability of needles delivered by DICs of major NGOs (CARE Bangladesh and Padakhep). However, it is satisfactory to learn that barriers other than these are insignificant enough to ignore, of which are limited hours of the program in the DICs, unavailability of outreach workers, inconvenience in regards to location of distribution and social barriers regards to outreach distribution. From Figure 3, it is suggestive that NEP is desired and successful enough to disregard the insignificance of the other barriers.

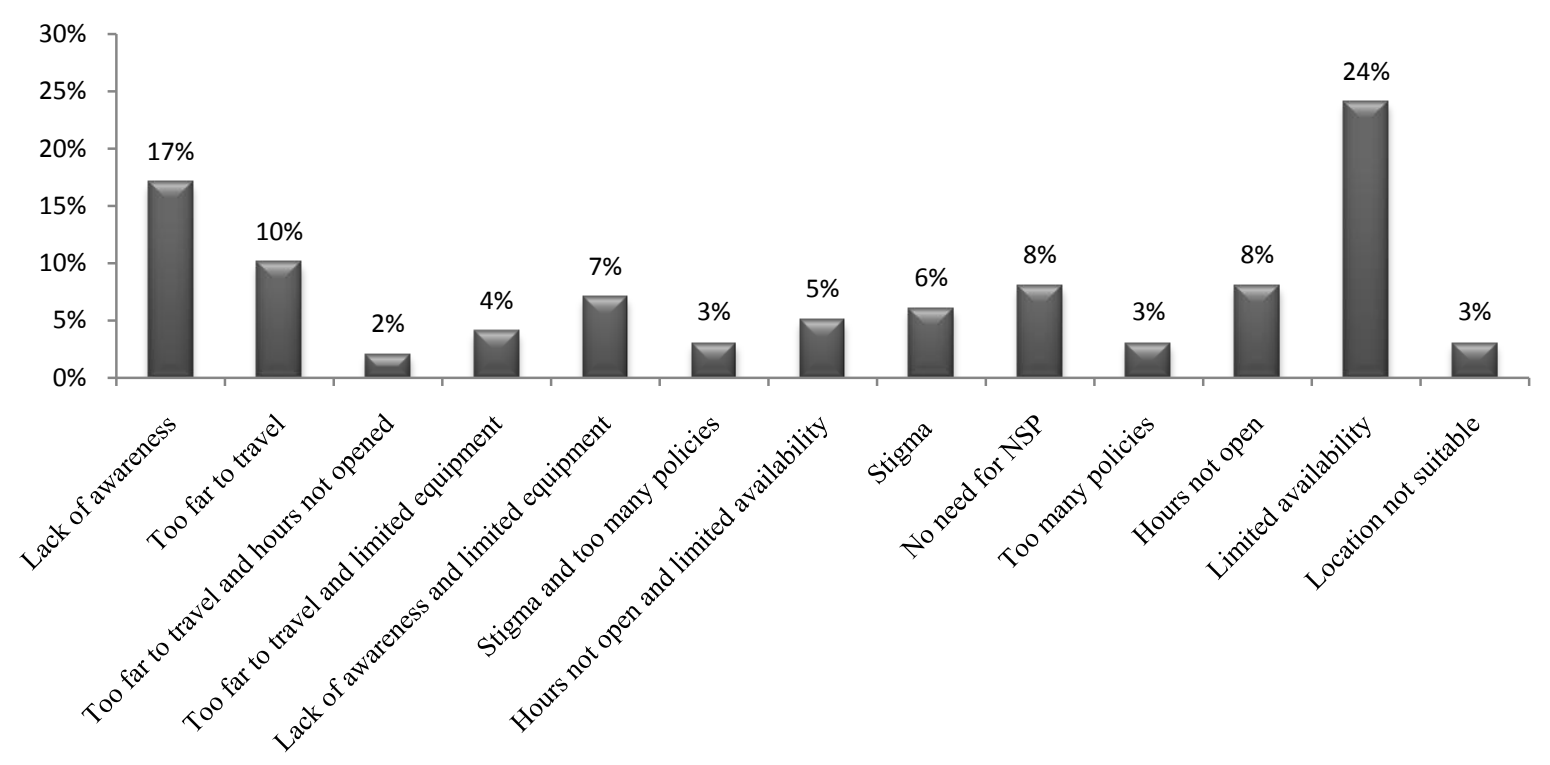

Figure 3. Demographics of barriers in needle exchange program

\section{Conclusion and Recommendation}

In this study the, first hypothesis was interrogative to the implementation of a needle-exchange program (NEP) leading to lower the sharing behavior among injecting drug users and results indicated that the current volume of NSP working across Dhaka city is not sufficient to meet the demands of IDUs and furthermore, due to limited hour of access, may have a limited effect in the promotion of safer behavior among IDUs. The second hypothesis queried if harm reduction policy influences service seeking patterns of IDUs and in this research harm reduction model has been applied to apprehend HIV and HCV risk behavior, recognizing that many IDUs are unable to stop injecting and intervention must occur to reduce the risk of HIV and HCV infection. The harm reduction model maintains that when IDUs are provided with logistic support and are threatened by any legal danger, they are more likely to resist risky behavior. This model is based on knowledge and means approach to change risk behaviors and service seeking patterns of IDUs. IDUs are provided with information that are needed and also with the means to make these changes. From this study it is found that most of the IDUs are visiting DICs for 3 to 6 years and they attend peer education on a regular basis. IDUs provided information that they get detoxification, treatment for abscess, STIs from DICs. In this case, this means sterile needles and syringes and other information resources influences safer administration of drugs. Harm reduction service leads to increase the awareness of HCV and HIV constructs the third hypothesis. Under the harm reduction model counseling and peer education are provided to raise awareness among IDUs about HIV and HCV. A large range of comments from the subjects of this study indicate that nearly the entire sample IDUs has a basic understanding about modes of transmission of HIV and HCV. However areas of misconception and confusion were identified regarding public toilet, mosquito bites, body piercing. Furthermore, the knowledge of risk factors alone does not necessarily ensure that IDUs perceived themselves to be at risk or lead to the avoidance of risk-taking.

The fourth hypothesis was probing about environment interventions causing the reduction of drug related harm. As IDUs are despised and ignored by general people it is important to set up safer environment where IDUs will 
be regulated when injecting to reduce vulnerability of sharing behavior and abscess. The fifth hypothesis was barriers toward the use of NSP (Needle Syringe Program) leading to increase drug related harm. The largest barrier to the respondents is limited availability of access to the outreach workers and drop in centers. Other barriers are also prevalent such as too many police around when they inject, stigma, limited equipment availability etc. These barriers are obstacles to NSEP services which increase the risk behavior of IDUs.

On the basis of these research findings, the following recommendations are proposed to decrease the risk of HIV and HCV transmission among the IDU population.

i. Blood borne infectious diseases other than HIV and HCV are often found among IDUs which should also be addressed by the committee policing activities, in existence of overlap issue.

ii. In all ranks of discussion and intervention, IDUs should be directly involved. Such involvement should result in the creation, provision of resources for and continuing support of drug user groups at federal, provincial, territorial and local levels.

iii. Awareness generation about hepatitis C and HIV are vital for successful implications of the model and should be increased through dissemination of a combination of information, education, and communication targeting high risk population.

iv. Drug abuse and substitution treatment following low threshold interventions should be commenced in a wide range of medical facilities that is calling for instantaneous response. Substitution is crucial for preventing initiation of injection, which is calling for further attention.

v. An all-out effort in regards to training and education must be initiated. It is crucial to train physicians, nurses, social workers, school educators, and other appropriate workers, including outreach workers, early intervention to youth contemplating injection drug use should be offered.

vi. Accurate and complete information should efficiently be transmitted to youth, helping them to make informed decisions. By efficiency, information homogeneity in absence of noise must be ensured.

vii. In order to successfully eliminate HIV and risks of other blood infused, a cooperative network of community policing, drug user groups and the social agencies must be integrated explicitly with highest order of response.

Community prevention programs need to be based on a comprehensive harm reduction model and should include needle exchange; safe injection sites; access to sterile drug use paraphernalia; greater access to detoxification and rehabilitation services, particularly for minors and young adults; well-coordinated and integrated health care and social services; user advocacy groups; life-skill programs; and low threshold substitution therapy. NGOs are consists of a range of projects and programs and has a wealth of knowledge. Liaison with these projects may provide valuable insights regarding empowerment and education.

\section{References}

British Columbia, Ministry of Health. (2005). Harm Reduction: A British Columbia Community Guide.

Bell, Kirsten, \& Salmon, A. (2011). What Women Who Use Drugs Have to Say About Ethical Research: Findings of an Exploratory Qualitative Study. Journal of Empirical Research on Human Research Ethics: An International Journal. University of California Press. 6(4), 84-98. http://dx.doi.org/10.1177/1747016112461731

Chowdhury, A. M. (2002). Bangladesh Madokdrobbo Niontron Ain Pranayan O Madokdrobbo Niontron Adhidoptor Protishther Potovumi. International Day Against Drug Abuse and Illicit Trafficking, Department of Narcotics Control, Segunbagicha, Dhaka, 2002.

Dickenson-Gomez, Julia. (2010). Structutal Factors Influencing Patterns of Drug Selling and Use and HIV Risk in the San Salvadore Metropolitan Area. Medical Anthropology Quarterly. American Anthropological Society, 24(2), 157-181. http://dx.doi.org/10.1111/j.1548-1387.2010.01095.x

Habib, S. E. (2004). Reducing HIV-Related Risk Behaviour Among Injecting Drug Users: The Harm Reduction Model in Bangladesh. Indian Journal of Community Medicine, 29(4), 175-177. http://www.doaj.org/doaj?func=openurl\&genre=article \&issn=09700218\&date $=2004 \&$ volume $=29 \&$ issue $=4$ \&spage $=175$

Habib, S. E. (2003). Understanding the context of risk practices among injecting drug users: Implications for hepatitis C prevention. Australian Journal of Social Issues, 38, 1-17. http://search.informit.com.au/documentSummary;dn=770422555550433;res=IELHSS 
Habib, S. E. (2009). Challenges and Risks: Harm Reduction, risk practices and the transmission of Hepatitis C in Sydney. Lambert Academic Publishing AG \& Co. KG, 2009.

Heather, N. (1993a). Application of harm-reduction principles to the treatment of alcohol problems. In N. Heather, A. Wodak, E. Nadelmann \& P. O'Hare (Eds.), Psychoactive Drugs and Harm Reduction: From Faith to Science, (pp. 168-183). London: Whurr Publishers. http://dx.doi.org/10.1080/02791072.1994.10472444

Hope et al. (2010). The extent of injection site infection in injecting drug users: findings from a national surveillance study. Epidemiology and Infection, 138(10), 1510-1518. http://dx.doi.org/10.1017/S0950268810000324

Inciardi, James A., \& Lana D. Harrison. (2009). Introduction: The Concept of Harm Reduction." Inciardi, James A. and Lana D. Harrison. Harm Reduction National and International Perspectives. London: Sage Publications, Inc. http://dx.doi.org/10.4135/9781452220680

James, Darlene. (September 2007). Harm Reduction Policy Background Paper. Albarta: Albarta Alcohol and Drug Abuse Commission (AADAC).

Marlatt, G. Alan. (1998). Harm Reduction: Pragmatic Strategies for Managing High-Risk Behaviors. Newyork: The Guilford Press.

Petersen, A. R., \& Lupton, D. (1996). The new public health: health and self in the age of risk. London:Sage.

Peterson, Peggy L., et al. (1998). Harm Reduction and HIV/AIDS Prevention. Harm Reduction: Pragmatic Strategies for Managing High-Risk Behaviors. London: The Guilford Press, 218-219.

Phillips, P., \& Joanne L. (2000). Dual Diagnosis- Does Harm Reduction Have a Role? International Journal of Drug Policy, 11, 279- 283. http://dx.doi.org/10.1016/S0955-3959(00)00058-X

Stimson, G. V., Chris F., \& Tim, R. (1998). The Rapid Assessment and Response guide on injecting drug use (IDU-RAR). World Health Organization. Geneva: World Health Organization.

Stimson, G. V., \& Lart, R. (1991). HIV, Drugs and public health in England: New world,old tunes.International Journal of the Addictions, 26(12), 1263-1277. URL: http://www.ncbi.nlm.nih.gov/pubmed/1787020

\section{$(\mathrm{cc}) \mathrm{BY}$}

This work is licensed under a Creative Commons Attribution 3.0 License. 